Check for updates

Cite this: RSC Adv., 2017, 7, 39699

Received 19th June 2017

Accepted 7th August 2017

DOI: $10.1039 / \mathrm{c} 7 \mathrm{ra06836k}$

rsc.li/rsc-advances

\title{
Fabrication of mechanically robust superhydrophobic steel surface with corrosion resistance property $\dagger$
}

\author{
Peng Wang, (D)* Tao Yao, Bo Sun, Tiejun Ci, Xiaoliang Fan and Huilong Han
}

In this research, a simple and cheap method was presented to make steel superhydrophobic. A mixture of antiformin solution and hydrogen peroxide was utilized to grow a porous structure on steel foil; the antiformin solution is much cheaper and more environmentally friendly than the use of strong acids. More interestingly, lotus-leaf-like hierarchical micro-nanostructures were formed after ultrasonic treatment. The superhydrophobic surface can be further prepared by surface modification, which could withstand sandpaper abrasion for $2.24 \mathrm{~m}$ under a pressure of $24.50 \mathrm{kPa}$ without losing superhydrophobicity. Moreover, the as-prepared superhydrophobic surface exhibits excellent selfcleaning and anti-corrosion properties.

\section{Introduction}

As is well known, steel has achieved extensive industrial applications due to its easy accessibility, cost efficiency, high fatigue strength and excellent machinability. Nevertheless, steel is easily oxidized and highly susceptible to corrosion in damp environments. It has been founded that the corrosion of steel is partly due to the contact with air and moisture. ${ }^{1,2}$ One possible solution is to make the steel surface superhydrophobic, which not only provides corrosion resistance property but also adds self-cleaning function to the surface.

In nature, water droplets exhibit a nearly spherical shape on the surface of lotus leaves and immediately roll off because of low adhesion. The rolling motion carries away dust and contaminants, which results in a self-cleaning property. Inspired by this phenomenon, superhydrophobic surfaces with large contact angles $\left(>150^{\circ}\right)$ and small sliding angles $\left(<10^{\circ}\right)$ have attracted a large amount of attention because of their potential applications in self-cleaning, ${ }^{3,4}$ oil/water separation, ${ }^{5-8}$ anti-icing, ${ }^{9,10}$ anticorrosion, ${ }^{11}$ and so forth. Among these applications, to improve the anti-corrosion performance on metal surface is an important research direction. Many methods have been introduced to prepare superhydrophobic metal surfaces, such as electrodepositing film, ${ }^{12,13}$ nanocasting technique, ${ }^{14}$ coating $\mathrm{SiO}_{2}$ or $\mathrm{TiO}_{2}$ nanoparticle, ${ }^{15,16}$ and chemical etching. ${ }^{17,18}$ Because of the simplicity, cost efficiency, and suitable for industrial applications, chemical etching is thought to be an effective method for preparing large-area superhydrophobic steel surfaces. ${ }^{19-21}$ Wang

School of Energy, Power and Mechanical Engineering, North China Electric Power University, Baoding, 071000, China. E-mail: wang.peng.ncepu@foxmail.com

$\dagger$ Electronic supplementary information (ESI) available. See DOI: $10.1039 / \mathrm{c} 7 \mathrm{ra} 06836 \mathrm{k}$ et al. prepared a superhydrophobic surface on steel through the combined etching of $\mathrm{H}_{2} \mathrm{O}_{2}$ and $\mathrm{HCl} / \mathrm{HNO}_{3} \cdot{ }^{22} \mathrm{Li}$ et al. fabricated a superhydrophobic steel surface by $\mathrm{HF} / \mathrm{H}_{2} \mathrm{O}_{2}$ etching. ${ }^{23}$ Nevertheless, preparing a superhydrophobic surface on steel using antiformin solution is still scarcely reported.

A crucial factor hindering the large scale application of superhydrophobic steel surfaces is their weak mechanical abrasion resistance. Although a large amount of superhydrophobic surfaces have been introduced, most of them are prone to be destroyed after a slight scratch, rubbing, and even finger contact. The reason may be that mechanical damage on the superhydrophobic surfaces tends to destroy the fragile micro-nano hierarchical structures. Recently, some researchers began to evaluate the mechanical durability. ${ }^{22-26}$ She et al. presented a robust superhydrophobic surface on magnesium alloy substrate, and the prepared surface showed a maximum abrasion distance of $0.70 \mathrm{~m}$ under a $1.2 \mathrm{kPa}$ pressure. ${ }^{25}$ Wang et al. prepared a robust superhydrophobic steel surface by $\mathrm{H}_{2} \mathrm{O}_{2}$ and $\mathrm{HCl} / \mathrm{HNO}_{3}$ etching, which could not endure the abrasion distance over $1.10 \mathrm{~m}$ under a $16 \mathrm{kPa}$ pressure. ${ }^{22}$ To the best of our knowledge, few studies about robust superhydrophobic steel surfaces under large pressure $(24.5 \mathrm{kPa})$ have been reported in the literature.

In this research, antiformin solution is introduced to prepare robust superhydrophobic steel surfaces. The fabrication process is composed from three steps: chemical immersion through the combination of antiformin and $\mathrm{H}_{2} \mathrm{O}_{2}$, ultrasonic treatment and surface modification. The present approach could be easily applied for large scale production, as the procedure is performed in an economical aqueous solution. In addition, the as-prepared surface exhibited superior anticorrosion, anti-abrasion and self-cleaning properties, which get rid of the major neckbottle for its practical application. 


\section{Experimental}

Materials

1045 steel (composition: C, 0.42-0.50; Si, 0.17-0.37; Mn, 0.500.80 ) with the size of $20 \mathrm{~mm} \times 20 \mathrm{~mm} \times 1 \mathrm{~mm}$ was used as the substrates. Ethanol (AR), acetone (AR), hexane (AR), $\mathrm{H}_{2} \mathrm{O}_{2}$ (30 wt\% in water), antiformin (CP, free alkali $7.0-8.0 \%$, active chlorine $\geq 5.2 \%$ ) were purchased from Sinopharm Chemical Reagent Co., Ltd., Shanghai, China. $1 H, 1 H, 2 H, 2 H$-perfluorooctyltriethoxysilane $\left(\mathrm{C}_{8} \mathrm{~F}_{13} \mathrm{H}_{4} \mathrm{Si}\left(\mathrm{OCH}_{2} \mathrm{CH}_{3}\right)_{3}\right.$, FAS) were purchased from Aladdin Reagent Co., Ltd, Shanghai, China. Polydimethylsiloxane (PDMS) is a two part crosslinkable resin (Sylgard®184, Dow Corning Co., Michigan, USA).

\section{The preparation of micro nano roughness}

Before using, steel substrates were ultrasonically cleaned in acetone, ethanol and deionized water, respectively, then dried in air for $30 \mathrm{~min}$. The etching solution was formed by adding $12.50 \mathrm{ml}$ antiformin solution into $10.00 \mathrm{ml} \mathrm{H}_{2} \mathrm{O}_{2}$ solution. Then, the cleaned steel substrate was immersed gently into the etching solution for $4 \mathrm{~h}$. After reaction, the substrate was rinsed with deionized water, and then dried in air.

\section{Ultrasonic treatment}

The steel substrate was immersed in deionized water, and then ultrasonically cleaned by a $100 \mathrm{~W}$ ultrasonic cleaner for $3 \mathrm{~min}$. The ultrasonic cleaned steel was further dried in air.

\section{Surface modification}

First, the aforementioned sample was immersed in an ethanol solution which contains $2.0 \mathrm{wt} \%$ FAS for $4 \mathrm{~h}$. Next, the sample was immersed in PDMS solution including $0.5 \mathrm{~g}$ PDMS, $0.1 \mathrm{~g}$ curing agent and $9.5 \mathrm{~g}$ hexane. After $3 \mathrm{~min}$, the sample was taken out, and cured at $80{ }^{\circ} \mathrm{C}$ for $2 \mathrm{~h}$.

\section{Characterization}

The surface morphologies of as-prepared samples were observed with a scanning electron microscope (SEM, Hitachi S3400N). Prior to SEM measurements, a thin Au layer (ca. $5 \mathrm{~nm}$ ) was deposited on the specimens by sputtering. The water contact angles (CAs) and sliding angles (SAs) were measured with a $5 \mu \mathrm{l}$ droplet of deionized water at ambient temperature on a contact angle measurement instrument (JC2000D, China). The average water CA and SA values were obtained by measuring the same sample at five different positions. The polarization curves were measured in $3.5 \mathrm{wt} \% \mathrm{NaCl}$ aqueous solution through a CHI600D electrochemical workstation (Shanghai $\mathrm{CH}$ instruments). A three-electrode system was adopted. The sample and a platinum electrode were employed as the working and counter electrodes, respectively. A saturated calomel electrode (SCE) was used as reference electrode. The scanning rate of polarization curves was $0.5 \mathrm{mV} \mathrm{s}^{-1}$.

\section{Results and discussion}

The surface morphology plays a key role in the preparation of superhydrophobic surfaces. Fig. 1a and b show the SEM images of surface morphologies of untreated steel at low and high magnifications, respectively. Most areas of the surface were smooth, and a small amount of defects exist. Fig. S1† shows the typical surface morphology of the steel substrates etched for different time intervals. After $4 \mathrm{~h}$ of etching in the mixture of $\mathrm{NaClO}$ and $\mathrm{H}_{2} \mathrm{O}_{2}$ solution, the steel surface showed a porous structure. As shown in Fig. 1c and d, the pore size ranged from nanoscale to microscale. We attributed this to the existence of $\mathrm{H}_{2} \mathrm{O}_{2}$, which generated $\mathrm{O}_{2}$ in the etching process. More interesting, ultrasonic treatment was adopted as a complementary texturing mechanism which can improve the surface's mechanical stability rather than degrade it. After ultrasonic treatment, micro sized cavities were presented on the surface as shown in Fig. 1e. Furthermore, nano sized features were created on the micro sized cavities as shown in Fig. 1f. This hierarchical morphology extensively mimicks the lotus leaf surface, where the rough microscale structure is covered by a nanoscale structure.

Chemical composition is another key factor to determine the superhydrophobicity of the surface. After ultrasonic treatment, the steel surface was further chemical modified to create superhydrophobicity. The EDS spectrum of modified steel surface is displayed in Fig. 2. From Fig. 2b, it is found that the Fe element exhibited a uniform distribution. The presence of

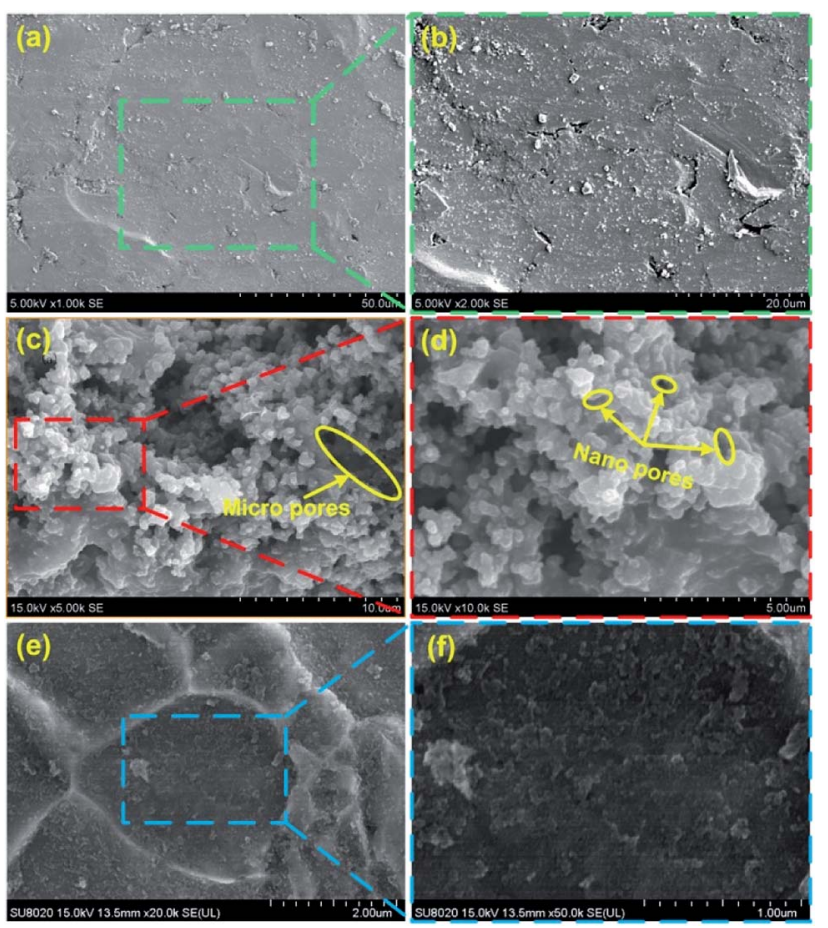

Fig. 1 SEM images of bare steel (steel-I), chemical etched steel (steelII), ultrasonic treated steel (steel-III): (a) steel-I, (b) magnified image of (a), (c) steel-II, (d) magnified image of (c), (e) steel-III, (f) magnified image of (e). 
(a)

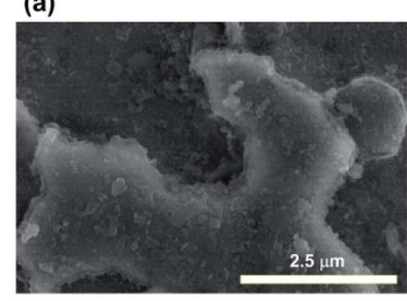

(c)

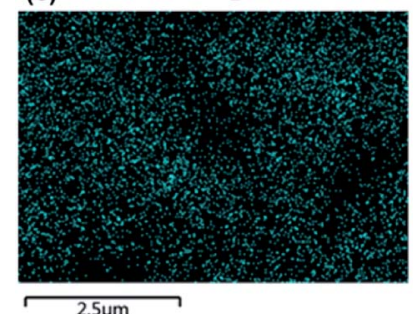

$2.5 \mu \mathrm{m}$

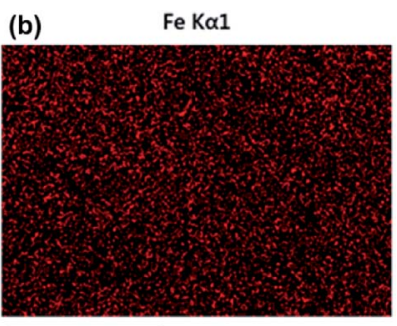

(d) $2.5 \mathrm{~mm} \quad \mathrm{oK} \alpha 1$

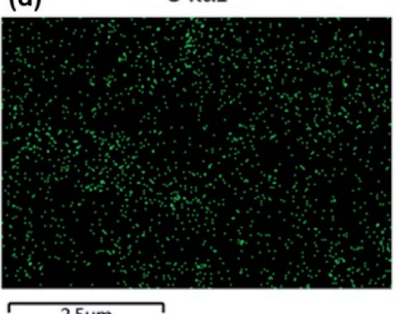

$2.5 \mu \mathrm{m}$

Fig. 2 EDS mapping images of $\mathrm{Fe}(\mathrm{b}), \mathrm{F}$ (c), and $\mathrm{O}$ (d) elements from the superhydrophobic surface (a).

fluorine element (Fig. 2c) confirmed the successful grafting of the FAS molecules. Moreover, the F element showed a heterogeneous distribution, which is basically in coordination with the bright area shown in the SEM image. The O element also exhibited a heterogeneous distribution. Through the comparison of Fig. $2 \mathrm{c}$ and d, it is found that the distribution of $\mathrm{O}$ and $\mathrm{F}$ showed a consistency. Then it is hard to detect $\mathrm{F}$ element in the regions without $\mathrm{O}$ element. We attribute this to the $-\mathrm{OH}$ groups which existed on the oxidized surface, which is found to be the prerequisite for surface grafting of silane..$^{22}$ Therefore, it is reasonable to deduce that the surface modification of FAS could only be performed at oxidized region, which is similar with other researches. ${ }^{27-30}$

The formation mechanism of the as-prepared superhydrophobic surface can be further elaborated in Fig. 3. As known, both $\mathrm{NaClO}$ and $\mathrm{H}_{2} \mathrm{O}_{2}$ show strong oxidizing behaviour in the reacting solution, which means that Fe could be oxidized into $\mathrm{Fe}_{2} \mathrm{O}_{3}$. Due to the existence of defect and crystallinity in the steel surface, the oxidizing process is not (a)

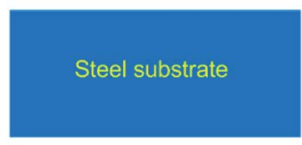

(d)

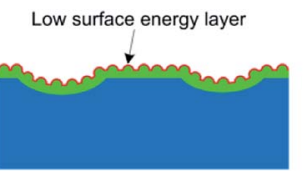

(b)

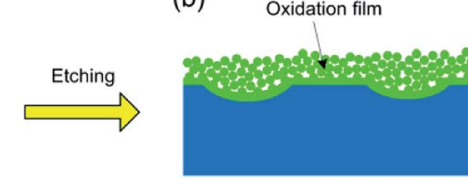

Ultrasonic treatment

(c)

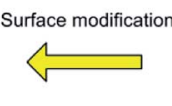

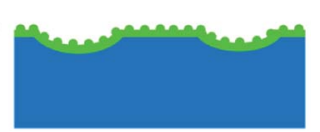

Fig. 3 The formation mechanism of the as-prepared superhydrophobic surface with hierarchical structure. uniform and micro-cavity structure tended to be formed. Moreover, a large amount of bubbles would generate in the etching process. We attribute this phenomenon to the existence of $\mathrm{H}_{2} \mathrm{O}_{2}$, which could generate $\mathrm{O}_{2}$ gas in the oxidizing process. The generation of bubbles further led to the formation of porous structure in the steel surface (Fig. 3b). After ultrasonic treatment, the fragile structure was removed. Then the steel surface was changed to lotus-leaf-like hierarchical micro-nanostructures (Fig. 3c). After the surface treatment of FAS and PDMS, a layer with low surface energy covered the hierarchical micro-nanostructures (Fig. 3d). In this research, the superhydrophobicity of the as-prepared surface derives from its rough surface with lotus-leaf-like hierarchical micronanostructures and the presence of low-surface-energy layer on it. Fig. 4 shows the wetting state for water droplets with different diameters on the as-prepared superhydrophobic surface, while all droplets keep nearly spherical shapes. According to the contact angle measurement, this kind of superhydrophobic coating has a high water contact angle of $163 \pm 2^{\circ}$ (Fig. 4). In addition, the water droplets can easily roll down the sample surface when the sliding angle is $6^{\circ}$, indicating a low contact angle hysteresis. ${ }^{31,32}$

The mechanical durability of superhydrophobic surfaces is a crucial factor which limits the widespread applications. Nevertheless, superhydrophobic surfaces with special micro/ nano structures are usually mechanically weak and easily destroyed. ${ }^{32,33}$ To solve this problem, lotus-leaf-like hierarchical micro-nanostructures were prepared on the steel surface. Using this structure, robust microscale bumps can provide protection to a more fragile nanoscale roughness. ${ }^{34}$ In this research, the sandpaper abrasion test was performed to systematically study the mechanically stability of the as-prepared superhydrophobic steel surface. As shown in Fig. 5a, the superhydrophobic steel $(2 \mathrm{~cm} \times 2 \mathrm{~cm})$ was attached to a $1 \mathrm{~kg}$ weight (a pressure of $24.5 \mathrm{kPa}$ ) with the help of commercial adhesive. Then, the sample facing down sandpaper (grit no. 150) was moved for $28 \mathrm{~cm}$ along the ruler by an external drawing force (Fig. $5 \mathrm{~b}$ and Movie S1 $\dagger$ ). The water contact angles and sliding angles were measured after each abrasion test cycle. Fig. $5 \mathrm{c}$ exhibits the change in contact angles and sliding angles as a function of the number of abrasion cycles. It can be found that the water

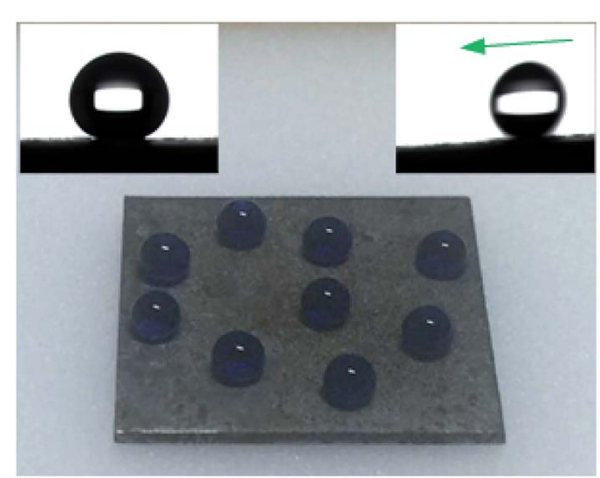

Fig. 4 The formation mechanism of the as-prepared superhydrophobic surface with hierarchical structure. 

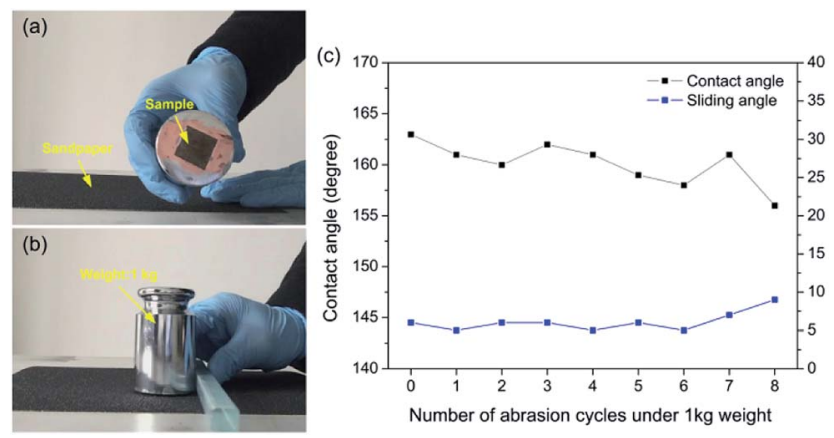

Fig. 5 ( $a$ and b) Illustration of one cycle of the abrasion test for the asprepared steel superhydrophobic surface under a $1 \mathrm{~kg}$ loading weight on sandpaper. (c) The contact angles and sliding angles as a function of abrasion cycles for the as-prepared superhydrophobic surface.

contact angles were between $150^{\circ}$ and $165^{\circ}$, and sliding angles varied between $5^{\circ}$ and $9^{\circ}$ through the abrasion cycles. When the abrasion cycle was further increased to 9 , some bad points could be found in Movie $\mathrm{S} 1 \uparrow$ where water droplets could not slip away. Therefore, the as-prepared steel surface retained superhydrophobicity after 9 sandpaper abrasion cycles $(2.24 \mathrm{~m})$ under a pressure of $24.5 \mathrm{kPa}$. It should be noted that the results displayed in this research showed better mechanical durability than other reported superhydrophobic metal surfaces, ${ }^{22-26}$ as shown in Table 1.

The self-cleaning ability is a crucial character of superhydrophobic surfaces for practical application. A selfcleaning test for the as-prepared superhydrophobic surface was carried out (Fig. 6 and Movie S2, ESI $\dagger$ ). Here, the carbon black powder was utilized as characteristic dust particles. ${ }^{35}$ As shown in Fig. 6a, the dust particles were spreaded onto the superhydrophobic steel surface (Fig. 6b). When a water droplet was dripped on the sample, they can smoothly roll down the surface and take away the dust at the same time (Fig. 6b and c). After water pouring processes, water droplets carried away the dust particles completely and left a clean surface (Fig. 6d). Therefore, the as-prepared steel superhydrophobic surface exhibited excellent self-cleaning property.

The polarization curves are useful methods to explore the impact of the superhydrophobic surfaces on the corrosion resistance of the steel substrate. Fig. 7 shows the polarization
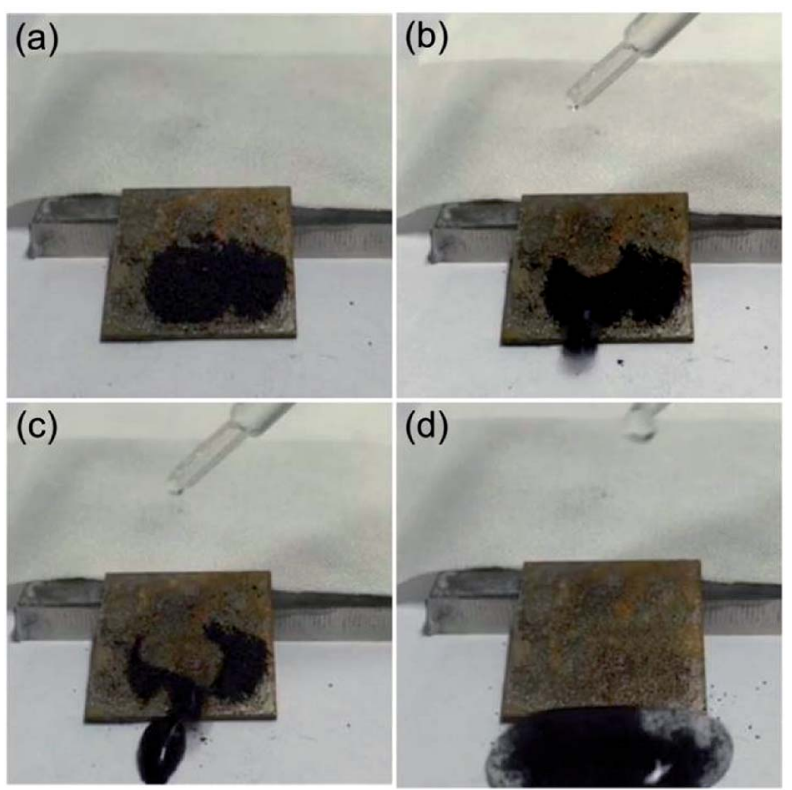

Fig. 6 Self-cleaning process on the as-prepared superhydrophobic surface: (a) the surface with carbon black as a model of contaminant; (b and c) the contaminated surface with water droplets on it; (d) the contaminated surface after water pouring process.

curves of bare steel substrate and modified superhydrophobic steel surface. Parameters such as corrosion potential $\left(E_{\text {corr }}\right)$ and corrosion current $\left(I_{\text {corr }}\right)$ can be obtained using the Tafel extrapolation. As shown in Fig. 7, the anti-corrosion ability was found to be improved on the superhydrophobic surface due to the lower $I_{\text {corr }}\left(12.706 \mu \mathrm{m} \mathrm{cm}^{-2}\right)$ and higher $E_{\text {corr }}(-0.511 \mathrm{~V})$ as compared to those of bare substrate $\left(I_{\text {corr }}=25.586 \mu \mathrm{m} \mathrm{cm}^{-2}\right.$, $E_{\text {corr }}=-1.017 \mathrm{~V}$ ), suggesting a good corrosion protection for the steel substrate. This result is consistent with previously published reports that superhydrophobic surfaces exhibit excellent anti-corrosion ability. ${ }^{36-38}$ When the superhydrophobic surfaces are immersed in a corrosive solution, air tends to be trapped in the lotus-leaf-like hierarchical micro-nanostructure of the asprepared superhydrophobic surface, and the trapped air behaves as a dielectric for a pure parallel plate capacitor and prevents the electron transfer between the electrolyte and the steel substrate. ${ }^{38}$

Table 1 Comparison of the mechanical durability of the prepared superhydrophobic coatings

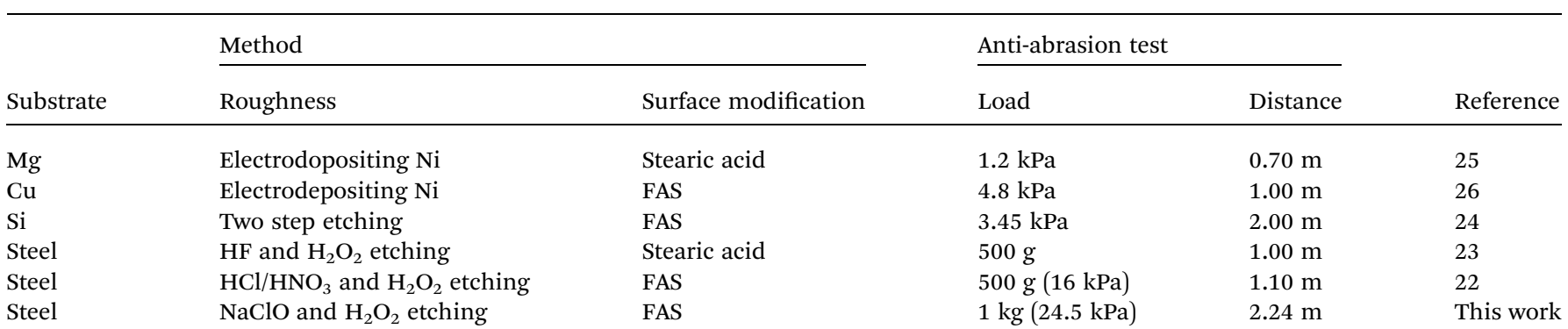




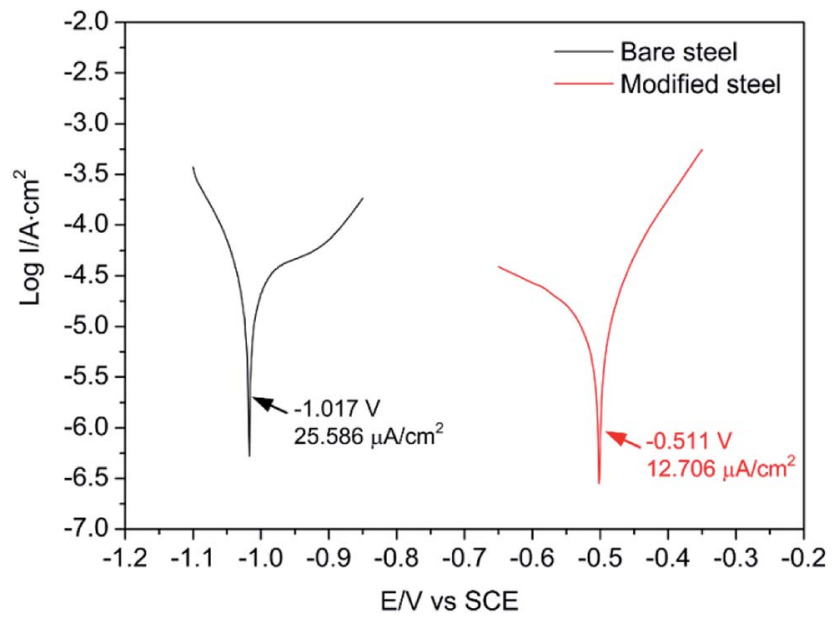

Fig. 7 Polarization curves of bare steel and as-prepared superhydrophobic steel.

\section{Conclusions}

In summary, mechanically robust superhydrophobic surface was fabricated on steel by a simple and low cost three-step method. Immersing steel into the mixture of antiformin and hydrogen peroxide was used to create porous structure. More interesting, lotus-leaf-like hierarchical micro-nanostructures were obtained after subsequent ultrasonic treatment. The superhydrophobic surface was further prepared by surface modification. Particularly, this superhydrophobic surface could withstand the sandpaper abrasion for $2.24 \mathrm{~m}$ under a pressure of $24.50 \mathrm{kPa}$. Moreover, this superhydrophobic surface shows distinguishing self-cleaning and anti-corrosion properties.

\section{Conflicts of interest}

There are no conflicts to declare.

\section{Acknowledgements}

This work was supported by Beijing Natural Science Foundation (3174058), National Nature Science Foundation of China (51607067), the Natural Science Foundation of Hebei Province (No. E2015502023), and the Fundamental Research Funds for the Central Universities (2017MS149).

\section{Notes and references}

1 Y. Lu, S. Sathasivam, J. Song, F. Chen, W. Xu, C. J. Carmalt and I. P. Parkin, J. Mater. Chem. A, 2014, 2, 11628.

2 K. Liu and L. Jiang, Annu. Rev. Mater. Res., 2012, 42, 231.

3 S. Nishimoto and B. Bhushan, RSC Adv., 2013, 3, 671.

4 D. Li and Z. Guo, RSC Adv., 2017, 7, 9169.

5 S. Taleb, T. Darmanin and F. Guittard, RSC Adv., 2014, 4, 3550.

6 C. R. Reshmi, S. P. Sundaran, A. Juraij and S. Athiyanathil, RSC Adv., 2017, 7, 2092.

7 J. Li, R. Kang, X. Tang, H. She, Y. Yang and F. Zha, Nanoscale, 2016, 8, 7638.
8 J. Li, L. Yan, X. Tang, H. Feng, D. Hu and F. Zha, Adv. Mater. Interfaces, 2016, 3, 1500770.

9 Y. Shen, J. Tao, H. Tao, S. Chen, L. Pan and T. Wang, RSC Adv., 2015, 5, 32813.

10 T. Moriya, K. Manabe, M. Tenjimbayashi, K. Suwabe, H. Tsuchiya, T. Matsubayashi, W. Navarrini and S. Shiratori, RSC Adv., 2016, 6, 92197.

11 J. Li, R. Wu, Z. Jing, L. Yan, F. Zha and Z. Lei, Langmuir, 2015, 31, 10702.

12 S. Khorsanda, K. Raeissi, F. Ashrafizadeh, M. A. Arenas and A. Conde, Appl. Surf. Sci., 2016, 364, 349.

13 A. V. Rao, S. S. Latthe, S. A. Mahadik and C. Kappenstein, Appl. Surf. Sci., 2011, 257, 5772.

14 C. Peng, K. Chang, C. Weng, M. Lai, C. Hsu, S. Hsu, Y. Hsu, W. Hung, Y. Wei and J. Yeh, Electrochim. Acta, 2013, 95, 192.

15 S. A. Mahadik, F. Pedraza and R. S. Vhatkar, J. Alloys Compd., 2016, 663, 487.

16 T. Isimjan, T. T. Wang and S. Rohani, Chem. Eng. J., 2012, 210, 182.

17 C. Chen, S. Yang, L. Liu, H. Xie, H. Liu, L. Zhu and X. Xu, J. Alloys Compd., 2017, 711, 506.

18 S. R. Yu, J. A. Liu, W. Diao and W. Li, J. Alloys Compd., 2014, 585, 689. 19 L. Liu, W. Liu, R. Chen, X. Li and X. Xie, Chem. Eng. J., 2015, 281, 804.

20 L. Liu, X. Feng and M. Guo, J. Phys. Chem. C, 2013, 117, 25519. 21 L. Liu, F. Xu and L. Ma, J. Phys. Chem. C, 2012, 116, 18722.

22 N. Wang, D. Xiong, Y. Deng, Y. Shi and K. Wang, ACS Appl. Mater. Interfaces, 2015, 7, 6260.

23 H. Zhang, J. Yang, B. Chen, C. Liu, M. Zhang and C. Li, Appl. Surf. Sci., 2015, 359, 905.

24 Y. Xiu, Y. Liu, D. W. Hess and C. Wong, Nanotechnology, 2010, 21, 155705.

25 Z. She, Q. Li, Z. Wang, L. Li, F. Chen and J. Zhou, Chem. Eng. J., 2013, 228, 415.

26 F. Su and K. Yao, ACS Appl. Mater. Interfaces, 2014, 6, 8762.

27 Z. Guo, F. Zhou, J. Hao and W. Liu, J. Am. Chem. Soc., 2005, 127, 15670.

28 N. Saleema, S. Sarkar, R. Paynter and X. Chen, ACS Appl. Mater. Interfaces, 2010, 2, 2500.

29 A. Hozumi, B. Kim and T. J. McCarthy, Langmuir, 2009, 25, 6834.

30 J. Li, Z. Jing, Y. Yang, F. Zha, L. Yan and Z. Lei, Appl. Surf. Sci., 2014, 289, 1.

31 P. Wang, M. Chen, H. Han, X. Fan, Q. Liu and J. Wang, J. Mater. Chem. A, 2016, 4, 7869.

32 X. Tian, T. Verho and R. H. A. Ras, Science, 2016, 352, 142.

33 Y. Lu, S. Sathasivam, J. Song, C. R. Crick, C. J. Carmalt and I. P. Parkin, Science, 2015, 347, 1132.

34 T. Verho, C. Bower, P. Andrew, S. Franssila, O. Ikkala and R. H. A. Ras, Adv. Mater., 2011, 23, 673.

35 P. Wang, T. Yao, B. Sun, X. Fan, S. Dong, Y. Bai and Y. Shi, Colloids Surf., A, 2017, 513, 396.

36 P. Wang, H. Han, J. Li, X. Fan, H. Ding and J. Wang, Appl. Phys. A, 2016, 122, 53.

37 M. Liang, Y. Wei, L. Hou, H. Wang, Y. Lia and C. Guo, J. Alloys Compd., 2016, 656, 311.

38 Y. Qing, C. Yang, C. Hu, Y. Zheng and C. Liu, Appl. Surf. Sci., 2015, 326, 48. 